\title{
Effect of ultrafiltration on extravascular lung water assessed by lung ultrasound in children undergoing cardiac surgery: a randomized prospective study
}

Mohamed Elayashy ${ }^{1 *}$ (D), Mai A. Madkour ${ }^{1}$, Ahmed Abdelaal Ahmed Mahmoud ${ }^{2}$, Hisham Hosny ${ }^{1}$, Amr Hussein ${ }^{1}$, Ahmed Nabih ${ }^{1}$, Ahmed Lofty ${ }^{1}$, Hamza Mohamed Hamza ${ }^{1}$, Passaint Hassan ${ }^{1}$, Mohamed Wagih ${ }^{1}$ and Ahmed Kareem Mohamed ${ }^{1}$

\begin{abstract}
Background: Increased lung water and the resultant atelectasis are significant pulmonary complications after cardiopulmonary bypass (CPB) in children undergoing cardiac surgery; these complications are observed after CPB than after anaesthesia alone. Ultrafiltration has been shown to decrease total body water and postoperative blood loss and improve the alveolar to arterial oxygen gradient and pulmonary compliance. This study investigated whether conventional ultrafiltration during CPB in paediatric heart surgeries influences post-bypass extravascular lung water (EVLW) assessed by lung ultrasound (LUS).

Methods: This randomized controlled study included 60 patients with congenital heart disease (ASA II-III), aged 1 to 48 months, with a body weight $>3 \mathrm{~kg}$. Conventional ultrafiltration targeting a haematocrit (HCT) level of $28 \%$ was performed on the ultrafiltration group, while the control group did not receive ultrafiltration. LUS scores were recorded at baseline and at the end of surgery. The $\mathrm{PaO} 2 / \mathrm{FiO}_{2}$ ratio (arterial oxygen tension divided by the fraction of inspired oxygen), urine output, and haemodynamic parameters were also recorded.
\end{abstract}

Results: LUS scores were comparable between the two groups both at baseline $(p=0.92)$ and at the end of surgery $(p=0.95)$; however, within the same group, the scores at the end of surgery significantly differed from their baseline values in both the ultrafiltration $(p=0.01)$ and non-ultrafiltration groups $(p=0.02)$.

The baseline $\mathrm{PaO} 2 / \mathrm{FiO} 2$ ratio was comparable between both groups. at the end of surgery, The $\mathrm{PaO} 2 / \mathrm{FiO} 2$ ratio increased in the ultrafiltration group compared to that in the non-ultrafiltration group, albeit insignificant $(p=0.16)$. no correlation between the $\mathrm{PaO} 2 / \mathrm{FiO} 2$ ratio and LUS score was found at baseline $(r=-0.21, p=0.31)$. On the other hand, post-surgical measurements were negatively correlated $(r=-0.41, p=0.045)$.

Conclusion: Conventional ultrafiltration did not alter the EVLW when assessed by LUS and oxygenation state. Similarly, ultrafiltration did not affect the urea and creatinine levels, intensive care unit (ICU) stays, ventilation days, or mortality.

Trial registration: Clinicaltrials.gov Identifier: NCT03146143 registered on 29-April-2017.

Keywords: Lung ultrasound, Ultrafiltration, Paediatric cardiac surgery, Extravascular lung water

\footnotetext{
* Correspondence: mohamedelayashy@kasralainy.edu.eg

${ }^{1}$ Department of Anesthesia and Intensive Care, Kasr Al Ainy Faculty of

Medicine, Cairo University, 7 Elshishiny St., El Maryotia, Faysal, Giza 12131,

Egypt

Full list of author information is available at the end of the article
}

(c) The Author(s). 2019 Open Access This article is distributed under the terms of the Creative Commons Attribution 4.0 International License (http://creativecommons.org/licenses/by/4.0/) which permits unrestricted use, distribution, and reproduction in any medium, provided you give appropriate credit to the original author(s) and the source, provide a link to the Creative Commons license, and indicate if changes were made. The Creative Commons Public Domain Dedication waiver (http://creativecommons.org/publicdomain/zero/1.0/) applies to the data made available in this article, unless otherwise stated. 


\section{Background}

In children, increased lung water and the resultant atelectasis are significant pulmonary complications after cardiac surgery with cardiopulmonary bypass (CPB). These complications are observed more after $\mathrm{CPB}$ than after anaesthesia alone [1]. interstitial oedema may lead to changes in the intrinsic elastic properties of the lung parenchyma during CPB. In combination with the action of constrictor mediators, oedema produces an obstructive process in the bronchi leading to both atelectasis and bronchospasm [2]. These pulmonary complications are usually associated with low arterial oxygen pressure $(\mathrm{PaO} 2)$ or high carbon dioxide pressure $(\mathrm{PaCO} 2)$, which may continue for several days, leading to prolonged mechanical ventilation [3].

$\mathrm{CPB}$ is also responsible for the activation of leukocytes and inflammatory processes resulting in alteration of capillary permeability as well as interstitial oedema [4]. Paediatric patients are more sensitive to factors like anticoagulation, haemodilution, hypothermia and the exposure of blood to non-endothelialised surfaces. Which initiate a systemic inflammatory response that increases the total body water and extravascular lung water (EVLW) [5].

Ultrafiltration targets the removal of inflammatory mediators throughout $\mathrm{CPB}$ together with modest haemoconcentration without prolonging the CPB [6]. Ultrafiltration has been shown to decrease total body water and postoperative blood loss and also to improve alveolar-to-arterial oxygen gradient and pulmonary compliance [7]. Compared to adults, children benefit more from ultrafiltration as they have an exaggerated inflammatory response from an increased bypass-surface to blood-volume ratio, higher exposure to blood transfusion, and less developed immune system [8]. This hypothesis is supported by a more pronounced suppression of inflammatory mediators by ultrafiltration in children compared to adults [9].

Lung ultrasound (LUS) can identify the most common pathologic abnormalities of the respiratory system encountered with high diagnostic accuracy including pneumothorax, pleural effusions, consolidation, and interstitial syndrome, which significantly affect patient management [10]. LUS also has a high diagnostic accuracy for identifying fluid overload and increased lung water and can therefore replace chest X-ray in paediatric patients [11].

In the current research we studied the effect of ultrafiltration during $\mathrm{CPB}$ on post-bypass EVLW using LUS and its effect on oxygenation. To the best of our knowledge, no previous study has assessed the effect of conventional ultrafiltration during $\mathrm{CPB}$ on EVLW by using bedside LUS in children undergoing cardiac surgery.

\section{Methods}

This is a single-centre, open-label, randomized controlled study conducted at Cairo University Paediatric Hospital after obtaining institutional Research Ethics Committee approval and written informed consent from patients' guardians. Patients were enrolled from 15th of May 2017 until 5th of October 2017. The study is also registered at ClinicalTrials.gov (NCT03146143).

Included in the study were 60 patients with congenital heart disease (ASA II-III), age ranged from 1 to 48 months, and with body weight $>3 \mathrm{~kg}$. Children with lung disease (asthma, bronchiectasis), those who were mechanically ventilated preoperatively, those with renal/hepatic impairment (values more than double the upper reference range), or those on preoperative inotropic support were excluded. a sequence generated by computer randomly allocated patients into ultrafiltration group $(n=30)$ and non-filtration (control) group $(n=30)$. Sealed opaque envelopes were used for concealment.

Preoperative assessment was performed according to our institutional protocol. Medication history revealed the use of thiazide diuretics as chronic medication to relieve pulmonary volume overload. Patients received intramuscular midazolam $0.3 \mathrm{mg} / \mathrm{kg}$ and atropine 0.02 $\mathrm{mg} / \mathrm{kg}$ as pre-medication $15 \mathrm{~min}$ before induction.

Induction of anaesthesia was established using fentanyl $1-5 \mu \mathrm{g} / \mathrm{kg}$ and ketamine $1-2 \mathrm{mg} / \mathrm{kg}$. Atracurium $0.5 \mathrm{mg} /$ $\mathrm{kg}$ facilitated endotracheal intubation and maintained intraoperative muscle relaxation as needed. Anaesthesia was maintained by expired sevoflurane $0.3-2 \%$ in the oxygen-air mixture (1:1 flow ratio) to obtain an $\mathrm{FiO} 2$ of $60 \%$. Ventilation was adjusted in volume-controlled mode with a respiratory rate targeting $\mathrm{PaCO} 2$ between 35 and $40 \mathrm{mmHg}$. The tidal volume was maintained at 8 to $10 \mathrm{~mL} / \mathrm{kg}$, and the positive end-expiratory pressure (PEEP) was $4 \mathrm{cmH} 2 \mathrm{O}$. The inspiratory-to-expiratory ratio was 1:2. A central venous catheter (Arrow International Inc., Reading, PA, USA) was inserted, and an arterial line was used for invasive blood pressure monitoring. On $\mathrm{CPB}$, anaesthesia was maintained with sevoflurane and midazolam $0.1 \mathrm{mg} / \mathrm{kg} / \mathrm{h}$ infusion.

In all patients, a median sternotomy was performed. $\mathrm{CPB}$ was initiated after full heparinization at a dose of $300-400 \mathrm{IU} / \mathrm{kg}$ to achieve an ACT of $450 \mathrm{~s}$ and standard aorta-bicaval cannulation. A membrane oxygenator (Minimax Plus; Medtronic, Inc., Anaheim, CA) and a non-pulsatile roller pump (model 10.10.00; Stôckert Instruments; Munich, Germany) were used. A small incision at the interatrial septum facilitated the insertion of the left atrial vent to vent the left heart. Priming fluids consisted of lactated Ringer's solution supplemented with heparin. Blood was added to the priming solution to achieve a haematocrit (HCT) of $28 \%$ at the start of $\mathrm{CPB}$. Moderate hypothermia $\left(28^{\circ} \mathrm{C}\right)$ was used during 
CPB. The aorta was completely cross-clamped, and myocardial preservation was achieved via antegrade cold enriched blood cardioplegia at a dose of $40 \mathrm{~mL} /$ $\mathrm{kg}$. Furosemide $1 \mathrm{mg} / / \mathrm{kg}$ was given after initiation of the bypass. Conventional ultrafiltration was performed after placement of the haemoconcentrator D575 with DHF02 (Sorin Group Italia, s.r.l., LIVANOVA) with its inlet connected to the arterial line and outlet to the cardiotomy or to the venous reservoir. After the initiation of $\mathrm{CPB}$ and stabilization of the haemodynamics according to the standardized parameters, hemofiltration was started and continued for up to 10 min before weaning from $\mathrm{CPB}$ to maintain the $\mathrm{HCT}$ value at $28 \%$.

After surgical repair, de-airing, rewarming and aortic declamping were performed, and the lungs were recruited with a continuous positive airway pressure (C-PAP) of $30 \mathrm{cmH} 2 \mathrm{O}$ for $40 \mathrm{~s}$. Then, the pre-bypass mechanical ventilation mode was resumed. The use of inotropes was guided by the patient's haemodynamic parameters. Dobutamine 5-10 $\mu \mathrm{g} / \mathrm{kg} / \mathrm{min}$, nitroglycerin $1-4 \mu \mathrm{g} / \mathrm{kg} / \mathrm{min}$, adrenaline $0.01-0.05 \mu \mathrm{g} / \mathrm{kg} / \mathrm{min}$ or milrinone $0.2-0.5 \mu \mathrm{g} / \mathrm{kg} / \mathrm{min}$ were used according to the pathophysiology and the intraoperative state of the patient. Heparin was reversed with protamine sulphate at a ratio of $1 \mathrm{mg}$ per $100 \mathrm{IU}$ of heparin.

The ultrafiltration group was subjected to conventional ultrafiltration targeting HCT level of $28 \%$ monitored by arterial blood gases, while the control group (non-filtration group) had no ultrafiltration and blood was transfused to target the same HCT level.

\section{Assessment of EVLW using LUS}

LUS was performed to diagnose EVLW. An M-Turbo SonoSite ultrasound system with a paediatric linear probe (frequency 13-6 MHz; Fujifilm, SonoSite, Inc., USA) was used. Chest ultrasound was performed using the twelve-region method. Intercostal spaces on each side were examined anteriorly (midclavicular line), laterally (anterior axillary line) and posteriorly (posterior axillary line) [12].

Scores of 0 to 3 were given for each region [13].

- Score 0: Normal aeration (N); standard sliding with A-lines or less than 3 B-lines;

- Score 1: Moderate loss of lung aeration; multiple visible B-lines with horizontal spacing between adjacent B-lines $\leq 7 \mathrm{~mm}$ (B7 lines);

- Score 2: Severe loss of lung aeration; multiple Blines fused together with horizontal spacing between adjacent B; lines $\leq 3 \mathrm{~mm}$ (B3 lines); and

- Score 3: Pulmonary consolidation; hypoechoic lung tissue with dynamic air bronchogram.
The final LUS score of the patient was the sum of each regional ultrasound score ranging from 0 to 36 . The LUS score was recorded at baseline $5 \mathrm{~min}$ after induction of anaesthesia and at the end surgery after skin closure.

The primary endpoint of the current study was the LUS score at the end of surgery. The $\mathrm{PaO} 2 / \mathrm{FiO} 2$ ratio (arterial oxygen tension divided by the fraction of inspired oxygen) and haemodynamic parameters (heart rate, blood pressure) at baseline and at the end of surgery were also recorded. The volume of ultrafiltrate and urine output were also recorded at the end of surgery and day 1 (D1) postoperatively. Urea and creatinine were recorded at baseline and D1 in the intensive care unit (ICU). Additionally, the duration of mechanical ventilation, mortality and patient characteristics were recorded.

\section{Statistical analysis}

Our main primary outcome (LUS score) was presented as the median (IQR), and haemodynamic parameters were presented as the mean (SD). A general linear model was performed for between-group comparisons of lung scores and the $\mathrm{PaO} 2 / \mathrm{FiO} 2$ ratio, and the same model with age adjustment as the covariate was applied for paired analysis of the same group variables. Unpaired and paired Student $\mathrm{t}$-tests were used to compare haemodynamics. Categorical data are presented as frequencies and were compared by using the chi square test. Correlations between the $\mathrm{PaO} 2 / \mathrm{FiO} 2$ ratio and LUS score were determined using the Pearson moment correlation equation. A $p$ value $<0.05$ was used as the level to determine statistically significant differences. All statistical calculations were performed using the SPSS version 23 (Statistical Package for the Social Science; SPSS, Inc., Chicago, IL, USA) statistical program. Data for 10 patients from our centre showed that the mean \pm SD of the lung score of these patients subjected to nonultrafiltration was $13.1 \pm 5$. With the assumption of a $30 \%$ difference between groups and by using $\mathrm{G}$ power software (version 3.1.3, Heinrich-Heine-Universität, Düsseldorf Germany) with power of 0.8 and 0.05 alpha error, the sample size was 27 per group, rolled up to 30 to allow for possible dropouts.

\section{Results}

Seventy participants aged four to 48 months were enrolled in the study. Four patients did not fulfil the inclusion criteria. Six patients refused to participate, and 60 patients completed the study (Fig. 1). Patients were assigned randomly into 2 groups: an ultrafiltration group ( $n=30$, received ultrafiltration during $\mathrm{CPB}$ ) and a nonfiltration (control) group $(\mathrm{n}=30)$. The patients' and clinical characteristics are presented in Tables 1 and 2. The 


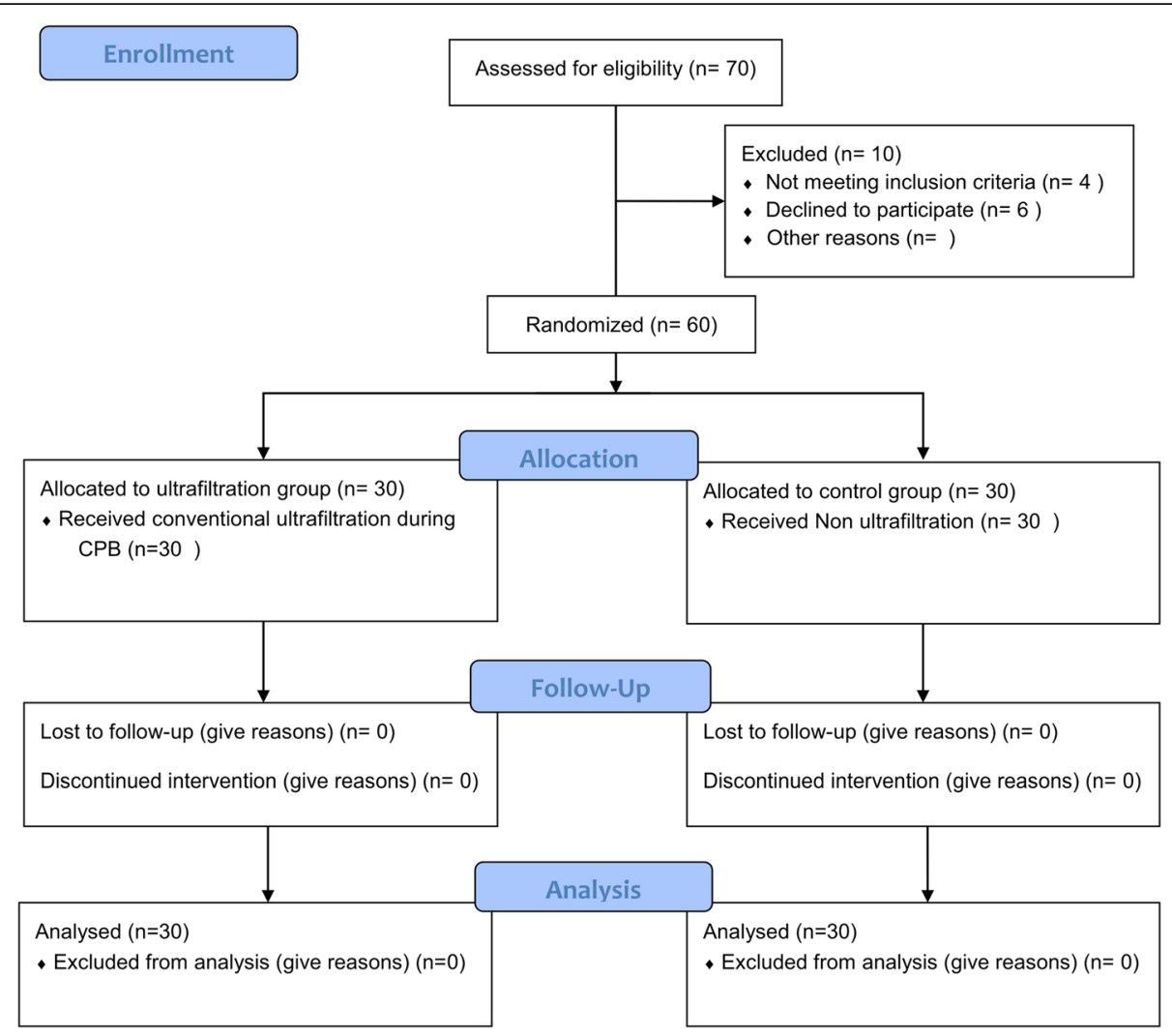

Fig. 1 CONSORT flow diagram showing the number of patients at each phase of the study

patients underwent different types of congenital heart surgeries (Table 3 ).

The median and IQR of LUS scores in the ultrafiltration and non-filtration groups were assessed at baseline (17 (10-24) vs $18.5(10.5-22.5))$ and at the end of surgery (13 (6-18) vs $14.5(7.5-17))$. Relative to the baseline, the paired analysis revealed that lung scores at the end of the surgery were significantly lower, indicating an improvement of lung scores in both the ultrafiltration $(p=0.01)$ and non-ultrafiltration groups $(p=0.02)$. However, the LUS scores were comparable between the two groups both at baseline $(p=0.92)$ and at the end of surgery $(p=0.95)$ (Fig. 2).

The baseline $\mathrm{PaO} 2 / \mathrm{FiO} 2$ ratio was comparable between the ultrafiltration and non-filtration groups at baseline $(220 \pm 102$ vs $205 \pm 119)$ and at the end of surgery $(223 \pm 109$ vs $248 \pm 125)$. The $\mathrm{PaO} 2 / \mathrm{FiO} 2$ ratio increased at the end of surgery in the ultrafiltration group compared to that in the non-ultrafiltration group, but there was no significant difference $(p=0.16)$ (Fig. 3). Within each group, the $\mathrm{P} / \mathrm{F}$ ratio remained comparable.

There was no correlation between the $\mathrm{PaO} 2 / \mathrm{FiO} 2$ ratio and LUS scores at baseline readings $(\mathrm{r}=-0.21, p=$ 0.31 ) (Fig. 4). At the end of surgery, a negative correlation was illustrated $(\mathrm{r}=-0.41, p=0.045)$ (Fig. 5). Heart rate (HR), systolic blood pressure (SBP), and diastolic blood pressure (DBP) were comparable both within and between groups at both time points (Table 4).

Between groups, urea and creatinine were comparable at baseline (ultrafiltration vs non-filtration; $18.5 \pm 5.2$ vs $18.6 \pm 6, p=0.99 ; 0.55 \pm 0.2$ vs $0.62 \pm 0.26, p=0.13$, respectively) and remained comparable at D1 postoperatively $(29.6 \pm 9$ vs $27.2 \pm 7.2, p=0.49 ; 0.82 \pm 0.25$ vs $0.95 \pm 0.15, p=0.18$, respectively). Within each group,

Table 1 Patient characteristics; value presented as the mean (SD) and numbers

\begin{tabular}{llll}
\hline & Ultrafiltration group $(N=30)$ & Non-filtration group $(N=30)$ & $P$ value \\
\hline Age (months) & $15.5 \pm 14$ & $19 \pm 14.8$ & 0.35 \\
Sex (male/female) & $(12 / 18)$ & $(14 / 16)$ & 0.30 \\
Weight $(\mathrm{kg})$ & $8.04 \pm 4.05$ & $9.2 \pm 3.7$ & 0.25 \\
Height $(\mathrm{cm})$ & $72.4 \pm 21.2$ & $78.5 \pm 24.1$ & 0.3 \\
\hline
\end{tabular}


Table 2 Duration of surgery, bypass duration, ventilation duration, ICU stay, ultrafiltration volume and volume of intraoperative fluid and blood; values are presented as the mean (SD) and numbers

\begin{tabular}{llll}
\hline & Ultrafiltration group $(\mathrm{N}=30)$ & Non-filtration group $(\mathrm{N}=30)$ & $P$ value \\
\hline Surgery duration (hours) & $4.5 \pm 0.6$ & $4.5 \pm 0.8$ & 1 \\
Bypass duration (min) & $87.6 \pm 33.7$ & $78 \pm 34.3$ & 0.27 \\
Ventilation days & $1.04 \pm 1.08$ & $1.07 \pm 1.2$ & 0.91 \\
ICU stay (days) & $3.2 \pm 1.3$ & $3.3 \pm 1.4$ & 0.77 \\
Ultrafiltration volume $(\mathrm{mL})$ & $580 \pm 362.3$ & & 0.71 \\
Intraoperative fluid $(\mathrm{mL})$ & $283.1 \pm 98.6$ & $199 \pm 67.2$ & 0.085 \\
Intraoperative blood $(\mathrm{mL})$ & $173.1 \pm 44.9$ &
\end{tabular}

$N$ number of patients, ICU intensive care unit

both urea and creatinine significantly increased at D1 compared to baseline values. (urea; $p<0.001$ ), (create; $p<0.001)$.

Intraoperatively, urine output was comparable between the ultrafiltration group $(328 \pm 221 \mathrm{~mL})$ and the nonfiltration group $(422 \pm 236 \mathrm{~mL}, p=0.11)$ and remained so at $\mathrm{D} 1$, being $321 \pm 175 \mathrm{~mL}$ in the ultrafiltration group and $400 \pm 145 \mathrm{~mL}$ in the non-filtration group, with $p=0.06$.

Finally, both groups were comparable regarding the incidence of postoperative complications. Two patients in the non-filtration group developed mild lung congestion defined by increased bilateral basal crepitations with increased broncho-vascular markings on chest X-ray. Two patients in the ultrafiltration group developed mild chest infection diagnosed by increased chest secretions with a change in sputum colour and fever up to $38.5{ }^{\circ} \mathrm{C}$. All 60 patients were discharged from the hospital without recorded mortality.

\section{Discussion}

In the current study, the lung U/S score showed no significant difference between the ultrafiltration and nonfiltration groups despite the improvement in the scores at the end of surgery compared to those at the beginning of surgery in both groups. Additionally, in the filtration group, the $\mathrm{PaO} 2 / \mathrm{FiO} 2$ ratio insignificantly increased at the end of surgery compared to patients who did not undergo filtration on CPB.

In a study by Mallamaci et al. [14], LUS was used to detect pulmonary congestion in haemodialysis patients through the detection of "lung comets", and it was found that standard ultrafiltration dialysis markedly reduced lung water and improved left ventricular performance in most cases. Similarly, Trezzi et al. [15] found a significant reduction in pulmonary B-lines following complete haemodialysis in patients on chronic dialysis, demonstrating the removal of volume overload. This reduction is significantly connected to the weight loss encountered during dialysis, emphasising a direct relationship between pulmonary B-lines and fluid balance.

Atelectasis caused by interstitial lung oedema remains the most significant effect of CPB on the lungs, inducing intravascular micro-aggregates to cause a decrease in $\mathrm{PO}_{2}$ (partial oxygen tension) and the $\mathrm{PaO} 2 / \mathrm{FiO} 2$ ratio and an increase in the intrapulmonary shunt after bypass [1]. This complication is known as earlier postperfusion lung syndrome, in which microaggregates, damage of blood cells and leukocyte activation are aggravated by preoperative pulmonary hypertension in paediatric patients with ventricular septal defects or a complete AV canal [16].

Huang et al. [17] showed that in paediatric patients the combined use of balanced and modified ultrafiltration could effectively increase the concentration of the blood, alter the increase in detrimental inflammatory mediators, attenuate the lung oedema and inflammatory pulmonary injury together with mitigation of the pulmonary function impairment. The Huang explanation was that conventional ultrafiltration is a useful mean for decreasing fluid accumulation in the lungs, but it is not a satisfactory method in the paediatric population because of the lower volume in the venous reservoir. The concern in children is that the priming volume dilutes

Table 3 Type and number of operations

\begin{tabular}{lll}
\hline Operations & Ultrafiltration group $(N=30)$ & Non-filtration group $(N=30)$ \\
\hline VSD closure & 22 & 18 \\
ASD, VSD closure & 1 & 2 \\
Complete AV canal repair & 5 & 9 \\
Transitional AV canal repair & 2 & 1
\end{tabular}

VSD ventricular septal defect, $A S D$ atrial septal defect, $A V$ atrioventricular 


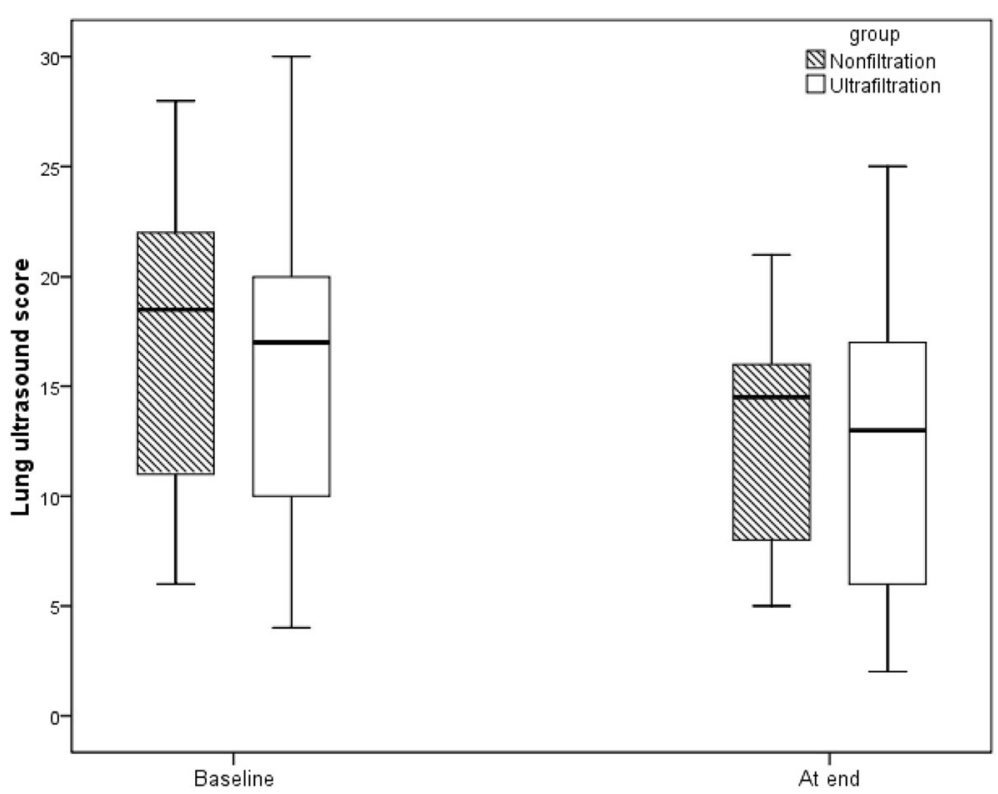

Fig. 2 LUS score at baseline and at the end of surgery. Values are expressed as the median and IQR

the patients' blood content 2 to 3 times due to their small circulating volume, whereas it only equals $1 / 3$ to $1 / 4$ of the total blood volume in the adult population. This dilution can be reduced by decreasing the number of crystalloids and adding blood to the priming fluid, by using diuretics or by using ultrafiltration. Conventional ultrafiltration is more commonly applied during CPB, aiming for haemoconcentration. However, modified ultrafiltration is applied after $C P B$ to remove inflammatory mediators such as IL6 and C3a [18].

Modified ultrafiltration was introduced to paediatric cardiac surgery because conventional ultrafiltration inadequately decreased the accumulated total body water and was less effective at removing inflammatory mediators. Two recent studies $[19,20]$ showed that the advantages of modified ultrafiltration over conventional ultrafiltration are only applicable to the immediate postbypass period but not to the postoperative outcome parameters. In the last decade, very few studies have revealed the benefits of ultrafiltration in paediatrics because priming with blood increases the HCT and the ultrafiltration rate is inversely proportional to HCT. In the early 1990s, the protocol was an HCT of $24 \%$ for $\mathrm{CPB}$, but now, perfusionists employ an HCT of $28 \%$ or even more for CPB. This difference in the HCT makes the use of ultrafiltration less efficient [21]. Thus, it might be wiser to control haemodilution earlier by minimizing crystalloids and priming with

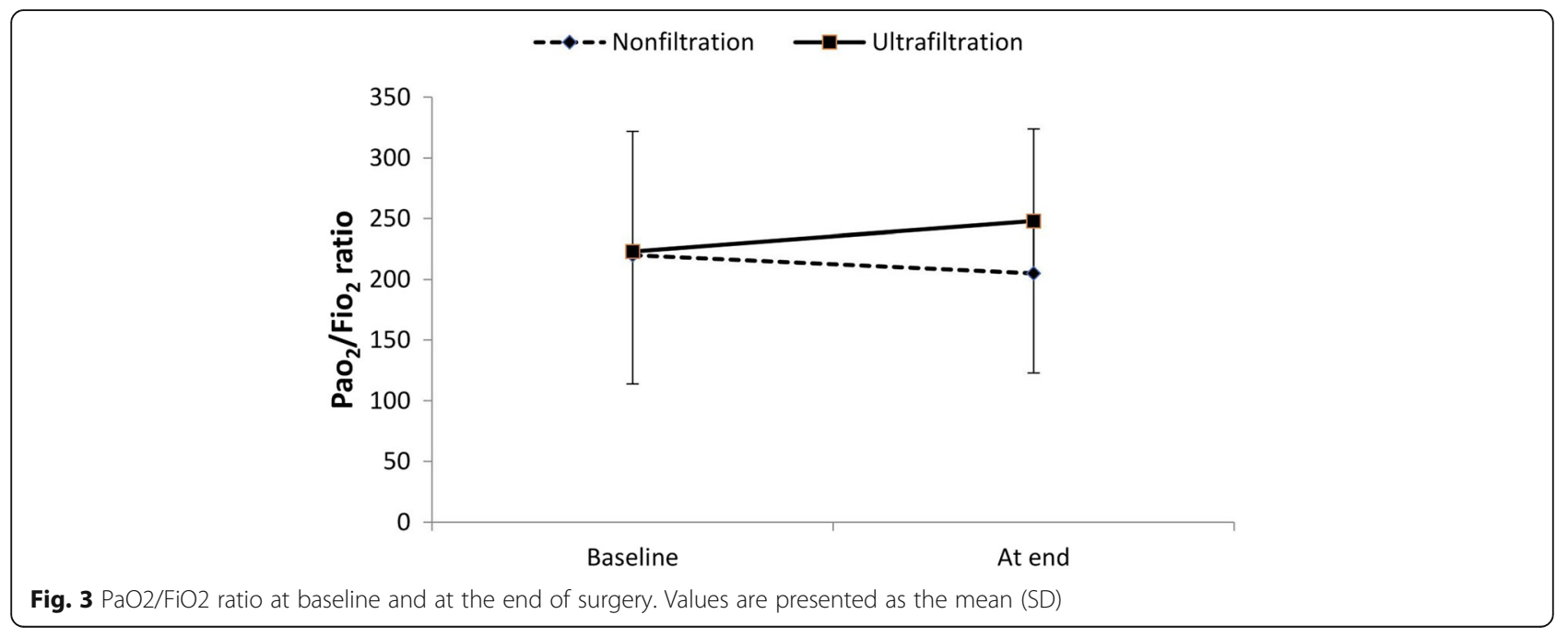




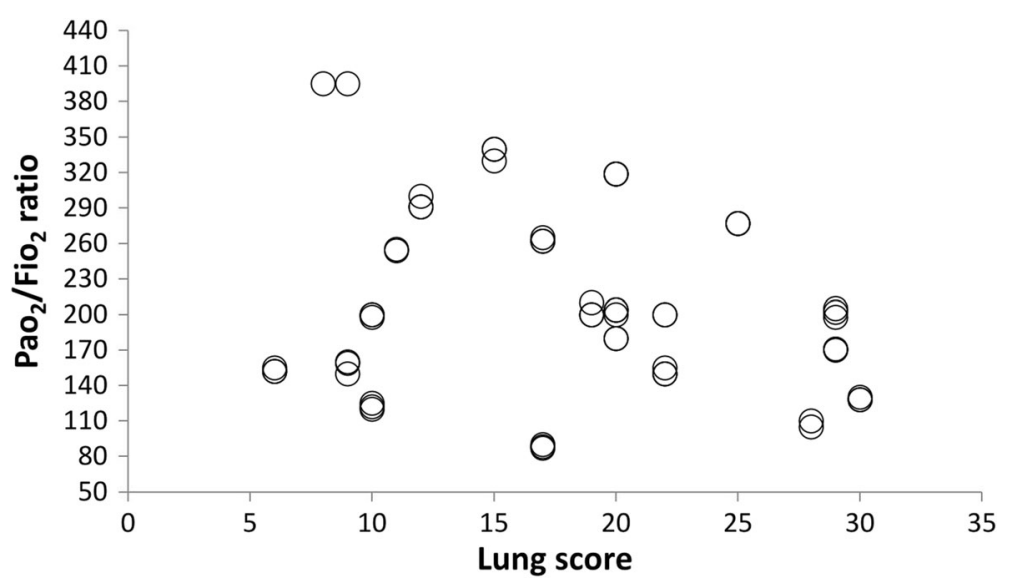

Fig. 4 Correlation between the $\mathrm{PaO} 2 / \mathrm{FiO} 2$ ratio and LUS score at baseline

blood than to control the haemodilution at a later phase.

The improvement of the lung score at the end of the operation compared to the beginning of the operation could be attributed to the manual ventilation with high inspiratory pressure at the end of the bypass to recruit collapsed lungs. Another main factor for improvement may be CHD repair and the elimination of pulmonary circulation overload and lung congestion. The use of diuretics after bypass may have also decreased plasma water in the alveolar interstitial space, thereby increasing pulmonary compliance and improving gas exchange across the respiratory membrane, which in turn might have been responsible for the improved $\mathrm{PaO} 2 / \mathrm{FiO} 2$ ratio and the lung score at the end of operation compared to those at baseline.

Naik et al. [22] postulated that the inefficiency of conventional ultrafiltration in reducing the total body water after CPB in paediatric patients occurs because the minimum prime volume is used in paediatrics. As per Naik et al. [22], the actual level in the reservoir remains very close to the alarm level, and thus, any filtration during bypass decreases the volume of the total circuit (patient and prime), resulting in the reduction of the actual fluid level in the venous reservoir already close to the alarm level. This means that more fluid must be added to the circuit, thereby negating the potential effects of ultrafiltration. Although no pulmonary data were measured in their study, this theory could explain the comparable lung scores at the end of the operation in the current study groups.

The use of ultrasound for diagnosing pleural and lung parenchyma abnormalities has increased in recent years [23]. LUS can be easily used to assess interstitial lung syndrome with increased EVLW. Increased EVLW may be diffuse (as in pulmonary oedema and adult respiratory distress syndrome [ARDS]) or focal (as lung contusion or pneumonia) [24]. LUS can also predict the volume and severity of EVLW, as there is a linear relationship between lung water and the number of B-lines.

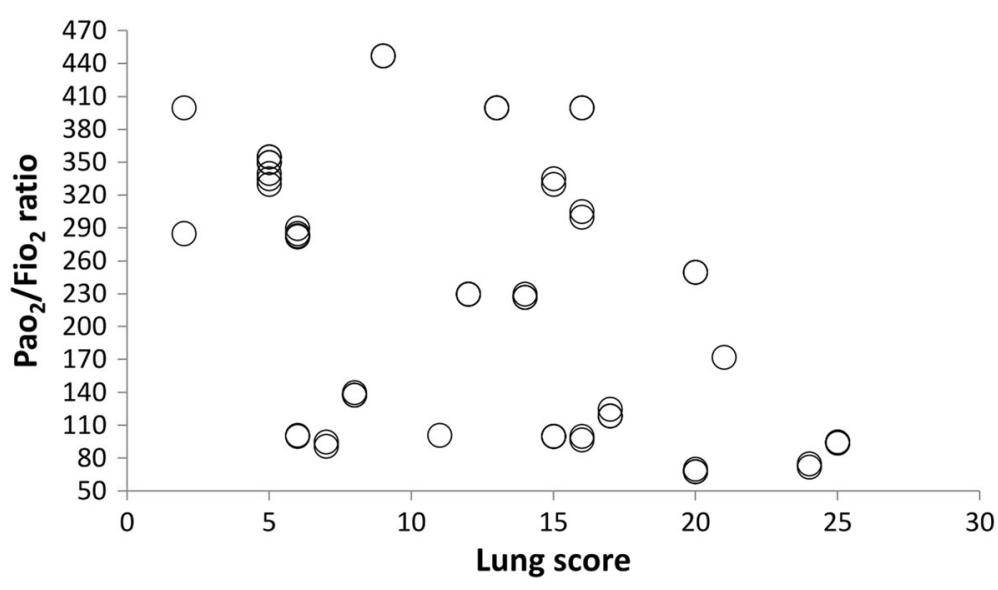

Fig. 5 Correlation between the $\mathrm{PaO} 2 / \mathrm{FiO} 2$ ratio and LUS score at the end of surgery 
Table 4 Mean (SD) of the haemodynamic parameters

\begin{tabular}{llll}
\hline & $\begin{array}{l}\text { Ultrafiltration group } \\
(N=30)\end{array}$ & $\begin{array}{l}\text { Non-filtration group } \\
(N=30)\end{array}$ & $P$ value \\
\hline HR & & $132 \pm 11.5$ & 0.18 \\
$\begin{array}{l}\text { Baseline } \\
\text { At the }\end{array}$ & $139.7 \pm 14$ & $140 \pm 14.5$ & 0.14 \\
end & & & \\
SBP & & $95.7 \pm 17.5$ & 0.82 \\
Baseline & $97.3 \pm 15.8$ & $90.4 \pm 15.2$ & 0.98 \\
$\begin{array}{l}\text { At the } \\
\text { end }\end{array}$ & $90.5 \pm 11.8$ & & \\
$\begin{array}{l}\text { DBP } \\
\text { Baseline }\end{array}$ & $55.6 \pm 15.2$ & & 0.91 \\
At the & $58.3 \pm 10.4$ & $56.3 \pm 11.4$ & 0.44 \\
end & & $55.1 \pm 9.7$ & \\
\hline
\end{tabular}

$H R$ heart rate, $S B P$ systolic blood pressure, $D B P$ diastolic blood pressure

Increasing lung water was initially represented by Blines, then as "white lung" formed by coalescent B-lines, and ultimately as alveolar consolidation [25]. Many studies [26-29] have demonstrated the high sensitivity and accuracy of LUS in diagnosing different pathologies, such as pneumothorax, pleural effusion, pneumonia and pulmonary embolism.

Urea and creatinine levels were comparable between groups in our study and remained so for the first postoperative day. In a study comparing conventional and modified ultrafiltration by Williams et al. [7], there was no significant difference in urea or creatinine levels between groups up to $48 \mathrm{~h}$ postoperatively. Increased urea and creatinine levels at D1 compared to baseline values in both groups might be explained by the combined effect of fluid administration and diuretic use postoperatively in the ICU.

In the current study, the $\mathrm{PaO} 2 / \mathrm{FiO} 2$ ratio was negatively correlated with LUS scores, which agrees with the findings of Konstantinos Stefanidis et al. [30], who reported that transthoracic lung sonography could detect non-aerated lung area changes during a PEEP trial of patients with early ARDS. The non-ventilated regions in the dependent lung areas were significantly reduced when the PEEP increased from 5 to 10 to $15 \mathrm{cmH}_{2} \mathrm{O}$. These changes produced a significant increase in arterial oxygen partial pressure $(74 \pm 15 \mathrm{mmHg}$ to $90 \pm 19$ $\mathrm{mmHg}$ to $102 \pm 26 \mathrm{mmHg} ; P<0.001$, respectively).

No significant difference in haemodynamics was observed in either group due to the deliberate use of inotropes and vasoactive drugs to maintain haemodynamic stability throughout the study period.

Our study has some limitations; ideally, lung scores and $\mathrm{PaO} 2 / \mathrm{FiO} 2$ ratios should have been recorded just before the start and at the end of bypass, but in the operating theatre environment, it would be impractical to apply ultrasound probes at these times. Further studies are required to assess the effect of modified ultrafiltration on the LUS score and on oxygenation.

\section{Conclusion}

Conventional ultrafiltration did not alter EVLW when assessed by LUS and the oxygenation state. Ultrafiltration did not affect the urea and creatinine levels, length of ICU stay, number of ventilation days or mortality.

\begin{abstract}
Abbreviations
ACT: Activated clotting time; ARDS: Adult respiratory distress syndrome; AV: Atrioventricular; CHD: Congenital heart disease; CPB: Cardiopulmonary bypass; EVLW: Extravascular lung water; ICU: Intensive care unit; LUS: Lung ultrasound score; $\mathrm{PaCO} 2$ : Carbon dioxide pressure; $\mathrm{PaO} 2$ : Arterial oxygen pressure; Pao2/Fio2 Ratio: Arterial oxygen tension divided by the fraction of inspired oxygen; PEEP: Positive end-expiratory pressure
\end{abstract}

Acknowledgements

None.

\section{Authors' contributions}

ME conceived of the study and participated in its design. MAM participated in the design of the study and drafted the manuscript. AAAM participated in the data collection and helped draft the manuscript. $\mathrm{HH}$ performed the statistical analysis and data interpretation and helped draft the manuscript. $\mathrm{AH}, \mathrm{AN}, \mathrm{AL}, \mathrm{HMH}$, and $\mathrm{PH}$ participated in the data collection. MW and AKM participated in the design of the study. All authors have read and approved the final manuscript.

\section{Funding}

This study has been funded by Cairo University Hospitals. The funding body contributed with research equipment. They did not have any influence on study design, data collection, analysis and interpretation of study data, or writing of the manuscript.

\section{Availability of data and materials}

Data are available from the authors (through contacting corresponding author) upon reasonable request after permission from Cairo University

\section{Ethics approval and consent to participate}

This study was approved by the Ethics Committee, Faculty of Medicine, Cairo University, with approval number N-19-2017. Informed written consent was obtained from all participants' guardians.

\section{Consent for publication}

Not applicable.

\section{Competing interests}

The authors declare that they have no competing interests.

\section{Author details}

'Department of Anesthesia and Intensive Care, Kasr Al Ainy Faculty of Medicine, Cairo University, 7 Elshishiny St., El Maryotia, Faysal, Giza 12131, Egypt. ${ }^{2}$ Department of Anesthesia, Faculty of Medicine, Beni-Suef University, Beni-Suef, Egypt.

Received: 19 January 2019 Accepted: 24 May 2019

Published online: 04 June 2019

\section{References}

1. Magnusson L, Zemgulis V, Wicky S, Tyden H, Thelin S, Hedenstierna G. Atelectasis is a major cause of hypoxemia and shunt after cardiopulmonary bypass. Anesthesiology. 1997:87:1153-63.

2. Babik B, Asztalos T, Peták F, Deák ZI, Hantos Z. Changes in respiratory mechanics during cardiac surgery. Anesth Analg. 2003;96:1280-7.

3. Ranieri VM, Suter PM, Tortorella C, De Tullio R, Dayer JM, Brienza A, Bruno F, Slutsky AS. Effect of mechanical ventilation on inflammatory mediators in patients with acute respiratory distress syndrome: a randomized controlled trial. Jama. 1999;282:54-61. 
4. Apostolakis E, Filos KS, Koletsis E, Dougenis D. Lung dysfunction following cardiopulmonary bypass. J Card Surg. 2010;25:47-55.

5. Seghaye MC, Grabitz RG, Duchateau J, Bussea S, Däbritz S, Koch D, Alzen G, Hörnchen $\mathrm{H}$, Messmer BJ, von Bernuth G. Inflammatory reaction and capillary leak syndrome related to cardiopulmonary bypass in neonates undergoing cardiac operations. J Thorac Cardiovasc Surg. 1996;112:687-97.

6. Gaynor JW. The effect of modified ultrafiltration on the postoperative course in patients with congenital heart disease. Semin Thorac Cardiovasc Surg Pediatr Card Surg Annu. 2003;6(1):128-39.

7. Williams GD, Ramamoorthy C, Chu L, Hammer GB, Kamra K, Boltz MG, Pentcheva K, McCarthy JP, Reddy VM. Modified and conventional ultrafiltration during pediatric cardiac surgery, clinical outcomes compared. J Thorac Cardiovasc Surg. 2006;132:1291-8.

8. Sever K, Tansel T, Basaran M, Kafalı E, Ugurlucan M, Ali Sayın O, Alpagut U,

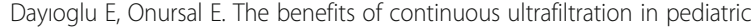
cardiac surgery. Scand Cardiovasc J. 2004;38:307-11.

9. Thapmongkol S, Masaratana P, Subtaweesin T, Sayasathid J, Thatsakorn K, Namchaisiri J. The effects of modified ultrafiltration on clinical outcomes of adult and pediatric cardiac surgery. Asian Biomed. 2015;9:591-9.

10. Lichtenstein DA. Ultrasound examination of the lungs in the intensive care unit. Pediatr Crit Care Med. 2009;10:693-8.

11. Ilinovi M, Saleem M, Romagnani P, Nazerian P, Hayes W. Lung ultrasound: a novel technique for detecting fluid overload in children on dialysis. Nephrol Dial Transplant. 2016;32:541-7.

12. Acosta CM, Maidana GA, Jacovitti D, Belaunzarán A, Cereceda S, Rae E, Molina A, Gonorazky S, Bohm SH, Tusman G. Accuracy of transthoracic lung ultrasound for diagnosing anesthesia-induced atelectasis in children. Anesthesiology. 2014;120:1370-9.

13. Zhao Z, Jiang $L, X i X$, Jiang $Q$, Zhu B, Wang $M$, Xing J, Zhang D. Prognostic value of extravascular lung water assessed with lung ultrasound score by chest sonography in patients with acute respiratory distress syndrome. BMC Pulm Med. 2015;15:98

14. Mallamaci F, Benedetto FA, Tripepi R, Rastelli S, Castellino P, Tripepi G,

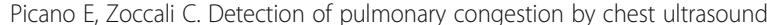
in dialysis patients. JACC Cardiovasc Imaging. 2010;3(6):586-94.

15. Trezzi M, Torzillo D, Ceriani E, Costantino G, Caruso S, Damavandi PT, Genderini A, Cicardi M, Montano N, Cogliati C. Lung ultrasonography for the assessment of rapid extravascular water variation: evidence from hemodialysis patients. Intern Emerg Med. 2013;8:409-15.

16. Westaby S, Fleming J, Royston D. Acute lung injury during cardiopulmonary bypass, the role of neutrophil sequestration and lipid peroxidation. ASAIO J. 1985;31:604-9

17. Huang H, Yao T, Wang W, Zhu D, Zhang W, Chen H, Fu W. Continuous ultrafiltration attenuates the pulmonary injury that follows open heart surgery with cardiopulmonary bypass. Ann Thorac Surg. 2003;76:136-40.

18. Guan Y, Wan C, Wang S, Sun P, Long C. Balanced ultrafiltration: inflammatory mediator removal capacity. Artif Organs. 2012;36(10):894-900.

19. Kuratani N, Bunsangjaroen P, Srimueang T, Masaki E, Suzuki T, Katogi T. Modified versus conventional ultrafiltration in pediatric cardiac surgery: a meta-analysis of randomized controlled trials comparing clinical outcome parameters. J Thorac Cardiovasc Surg. 2011;142(4):861-7.

20. Xing W, Liu YL, Yang KH, Song B, Han B. Clinical effects of modified ultrafiltration during pediatric cardiac surgeny: a systematic review. 2010; 1665-1669.

21. Harvey B, Shann KG, Fitzgerald D, Mejak B, Likosky DS, Puis L, Baker RA, Groom RC. International pediatric perfusion practice: 2011 survey results. J Extra Corpor Technol. 2012;44(4):186.

22. Naik SK, Knight A, Elliott MJ. A successful modification of ultrafiltration for cardiopulmonary bypass in children. Perfusion. 1991;6:41-50.

23. Koenig SJ, Narasimhan M, Mayo PH. Thoracic ultrasonography for the pulmonary specialist. Chest. 2011;140:1332-41.

24. Hew M, Tay TR. The efficacy of bedside chest ultrasound: from accuracy to outcomes. Eur Respir Rev. 2016:25(141):230-46.

25. Via G, Lichtenstein D, Mojoli F, Rodi G, Neri L, Storti E, Klersy C, lotti G, Braschi A. Whole lung lavage: a unique model for ultrasound assessment of lung aeration changes. Intensive Care Med. 2010;36(6):999-1007.

26. Ye X, Xiao H, Chen B, Zhang S. Accuracy of lung ultrasonography versus chest radiography for the diagnosis of adult community-acquired pneumonia: review of the literature and meta-analysis. PLoS One. 2015; 10(6):e0130066.

27. Nazerian P, Volpicelli G, Vanni S, Gigli C, Betti L, Bartolucci M, Zanobetti M, Ermini FR, lannello C, Grifoni S. Accuracy of lung ultrasound for the diagnosis of consolidations when compared to chest computed tomography. Am J Emerg Med. 2015;33(5):620-5.

28. Ebrahimi A, Yousefifard M, Kazemi HM, Rasouli HR, Asady H, Jafari AM, Hosseini M. Diagnostic accuracy of chest ultrasonography versus chest radiography for identification of pneumothorax: a systematic review and meta-analysis. Tanaffos. 2014;13(4):29.

29. Mathis G, Bitschnau R, Gehmacher O, Scheier M, Kopf A, Schwärzler B, Amann T, Doringer W, Hergan K. Chest ultrasound in diagnosis of pulmonary embolism in comparison to helical CT. Ultraschall Med. 1999; 20(02):54-9.

30. Stefanidis K, Dimopoulos S, Tripodaki ES, Vitzilaios K, Politis P, Piperopoulos $P$, Nanas S. Lung sonography and recruitment in patients with early acute respiratory distress syndrome: a pilot study. Crit Care. 2011;15:R185.

\section{Publisher's Note}

Springer Nature remains neutral with regard to jurisdictional claims in published maps and institutional affiliations.
Ready to submit your research? Choose BMC and benefit from:

- fast, convenient online submission

- thorough peer review by experienced researchers in your field

- rapid publication on acceptance

- support for research data, including large and complex data types

- gold Open Access which fosters wider collaboration and increased citations

- maximum visibility for your research: over $100 \mathrm{M}$ website views per year

At BMC, research is always in progress.

Learn more biomedcentral.com/submissions 